${ }^{1}$ Division of Public Health Sciences, Wake Forest University School of Medicine, Winston-Salem, NC 27157-1063, USA

${ }^{2}$ National Heart Lung and Blood Institute, National Institute of Health, Bethesda, MD 20892 USA

${ }^{3}$ McMaster University and Hamilton Health Sciences, Population Health Research Institute, Hamilton, Ontario L8L 2X2, Canada

${ }^{4}$ Department of Medicine University of Minnesota, Minneapolis, MN 55455, USA

${ }^{5}$ International Diabetes Center at Park Nicollet, Minneapolis, MN 55416-2699, USA

${ }^{6}$ Section of Endocrinology and Metabolism, Department of Internal Medicine, Wake Forest University School of Medicine, Winston-Salem, NC 27157, USA

${ }^{7}$ Memphis Veterans Affairs Medical Center, Memphis, TN 38104, USA

${ }^{8}$ Whittier Institute for Diabetes, La Jolla, CA 92037, USA

${ }^{9}$ Division of Endocrinology, Metabolism, and Nutrition, Duke University Medical Center, Durham, NC 27710, USA

${ }^{10}$ Case Western Reserve University, Cleveland, $\mathrm{OH} 44106$, USA

${ }^{11}$ Department of Medicine, Division of Endocrinology, University of North Carolina, Chapel Hill, NC 27514, USA

${ }^{12}$ HealthPartners Research Foundation, Minneapolis, MN 55440-1524, USA

${ }^{13}$ Department of Medicine, Schulich School of Medicine and Dentistry, University of Western Ontario, London, Ontario N6A 5C1, Canada

${ }^{14}$ National Institute of Diabetes and Digestive and Kidney Diseases, National Institutes of Health, Bethesda, MD 20892 , USA

${ }^{15}$ Albert Einstein College of Medicine, Jacobi Medical Center, Bronx, NY 10461, USA

Correspondence to: M E Miller mmiller@wfubmc.edu

\section{The effects of baseline characteristics, glycaemia treatment approach, and glycated haemoglobin concentration on the risk of severe hypoglycaemia: post hoc epidemiological analysis of the ACCORD study}

Michael E Miller, professor of biostatistics, ${ }^{1}$ Denise E Bonds, medical officer, ${ }^{2}$ Hertzel C Gerstein, professor of medicine and clinical epidemiology \& biostatistics, ${ }^{3}$ Elizabeth R Seaquist, professor of medicine, ${ }^{4}$ Richard M Bergenstal, executive director, ${ }^{5}$ Jorge Calles-Escandon, associate professor of medicine, ${ }^{6} \mathrm{R}$ Dale Childress, clinical assistant professor of medicine, ${ }^{7}$ Timothy E Craven, senior biostatistician, ${ }^{1}$ Robert M Cuddihy, medical director, ${ }^{5}$ George Dailey, head of diabetes research, ${ }^{8}$ Mark N Feinglos, professor of medicine, ${ }^{9}$ Farmarz IsmailBeigi, professor of medicine, ${ }^{10}$ Joe F Largay, clinical instructor of medicine, ${ }^{11}$ Patrick J O'Connor, senior clinical investigator, ${ }^{12}$ Terri Paul, associate professor of medicine, ${ }^{13}$ Peter J Savage, senior adviser for clinical diabetes studies,${ }^{14}$ Ulrich K Schubart, professor of medicine, ${ }^{15}$ Ajay Sood, assistant professor of medicine, ${ }^{10}$ Saul Genuth, professor of medicine, ${ }^{10}$ for the ACCORD Investigatorsfor the ACCORD Investigators

\section{ABSTRACT}

Objectives To investigate potential determinants of severe hypoglycaemia, including baseline characteristics, in the Action to Control Cardiovascular Risk in Diabetes (ACCORD) trial and the association of severe hypoglycaemia with levels of glycated haemoglobin (haemoglobin $A_{1}$ ) achieved during therapy. Design Post hoc epidemiological analysis of a double $2 \times 2$ factorial, randomised, controlled trial.

Setting Diabetes clinics, research clinics, and primary care clinics.

Participants 10209 of the 10251 participants enrolled in the ACCORD study with type 2 diabetes, a haemoglobin $A_{1 C}$ concentration of $7.5 \%$ or more during screening, and aged $40-79$ years with established cardiovascular disease or 55-79 years with evidence of significant atherosclerosis, albuminuria, left ventricular hypertrophy, or two or more additional risk factors for cardiovascular disease (dyslipidaemia, hypertension, current smoker, or obese).

Interventions Intensive (haemoglobin $\mathrm{A}_{1 \mathrm{C}}<6.0 \%$ ) or standard (haemoglobin $A_{1 c}$ 7.0-7.9\%) glucose control.

Main outcome measures Severe hypoglycaemia was defined as episodes of "low blood glucose" requiring the assistance of another person and documentation of either a plasma glucose less than $2.8 \mathrm{mmol} / \mathrm{l}(<50 \mathrm{mg} / \mathrm{dl})$ or symptoms that promptly resolved with oral carbohydrate, intravenous glucose, or glucagon. Results The annual incidence of hypoglycaemia was $3.14 \%$ in the intensive treatment group and $1.03 \%$ in the standard glycaemia group. We found significantly increased risks for hypoglycaemia among women $(P=0.0300)$, African-Americans ( $\mathrm{P}<0.0001$ compared with
non-Hispanic whites), those with less than a high school education ( $\mathrm{P}<0.0500$ compared with college graduates), aged participants ( $\mathrm{P}<0.0001$ per 1 year increase), and those who used insulin at trial entry $(\mathrm{P}<0.0001)$. For every $1 \%$ unit decline in the haemoglobin $\mathrm{A}_{1 \mathrm{C}}$ concentration from baseline to 4 month visit, there was a $28 \%(95 \% \mathrm{Cl}$ $19 \%$ to $37 \%$ ) and $14 \%$ ( $4 \%$ to $23 \%$ ) reduced risk of hypoglycaemia requiring medical assistance in the standard and intensive groups, respectively. In both treatment groups, the risk of hypoglycaemia requiring medical assistance increased with each $1 \%$ unit increment in the average updated haemoglobin $\mathrm{A}_{1 \mathrm{C}}$ concentration (standard arm: hazard ratio $1.76,95 \% \mathrm{Cl}$ 1.50 to 2.06 ; intensive arm: hazard ratio $1.15,95 \% \mathrm{Cl}$ 1.02 to 1.21 ).

Conclusions $A$ greater drop in haemoglobin $A_{1 C}$ concentration from baseline to the 4 month visit was not associated with an increased risk for hypoglycaemia. Patients with poorer glycaemic control had a greater risk of hypoglycaemia, irrespective of treatment group. Identification of baseline subgroups with increased risk for severe hypoglycaemia can provide guidance to clinicians attempting to modify patient therapy on the basis of individual risk.

Trial registration ClinicalTrials.gov number NCT00000620.

\section{INTRODUCTION}

Hypoglycaemia is the most important adverse effect of intensive glycaemic management in patients with diabetes. Severe episodes can be accompanied by confusion, disorientation, irrational behaviour, convulsions, coma, permanent impairment of brain function, serious injury, and even death. Hypoglycaemia is 
particularly dangerous if it occurs while patients are driving or operating potentially hazardous machinery, and in those living alone with no one to provide assistance. Asymptomatic episodes may be accompanied by silent myocardial ischaemia. ${ }^{1}$ Loss of warning signs (hypoglycaemia unawareness) and severe episodes become more prevalent as glycaemia control improves to the point that glucose levels are at normal or near normal levels. Indeed, hypoglycaemia has been identified as the limiting factor that prevents patients with diabetes from achieving excellent glycaemic control. ${ }^{23}$

The Diabetes Control and Complications Trial (DCCT) reported 62 episodes of severe hypoglycaemia requiring assistance for treatment per 100 person years in patients with type 1 diabetes treated intensively to a target of normoglycaemia, ${ }^{4}$ which was three times higher than the event rate in patients on standard treatment. Although the incidence of severe hypoglycaemia is typically lower in patients with type 2 diabetes than in those with type 1 diabetes, it is not inconsequential. Estimates of the incidence of severe hypoglycaemia in patients with type 2 diabetes vary, depending on definitions and methods of ascertainment. The incidence of severe hypoglycaemia in intensively treated patients in clinical trials ranges from as low as 0.7 events per 100 person years in the Action in Diabetes and Vascular Disease: Preterax and Diamicron Modified Release Controlled Evaluation (ADVANCE) study ${ }^{5}$ and 1.8 patients per 100 person years with insulin treatment in the UK Prospective Diabetes Study (UKPDS), ${ }^{6}$ to nine episodes with impaired consciousness per 100 person years in the Veterans Affairs Diabetes Trial (VADT). ${ }^{7}$ In epidemiological studies, higher frequencies of $12,{ }^{8} 15,{ }^{9}$ $28,{ }^{10}$ and $35^{11}$ episodes per 100 person years have been reported. Most severe episodes occur with insulin or sulphonylurea treatment. ${ }^{12}$

The Action to Control Cardiovascular Risk in Diabetes (ACCORD) trial was designed to test the hypothesis that reducing blood glucose concentrations to near normal levels in adults with type 2 diabetes at high risk of a cardiovascular event would result in a reduction in non-fatal and fatal cardiovascular disease. The ACCORD glycaemia trial compared intensive treatment aimed at achieving normoglycaemia (target glycated haemoglobin (haemoglobin $\mathrm{A}_{1 \mathrm{C}}$ ) concentration $<6.0 \%$ ) with standard treatment (target haemoglobin $\mathrm{A}_{1 \mathrm{C}}$ level 7.0-7.9\%) in individuals with type 2 diabetes aged either 40-79 years with established cardiovascular disease or 55-79 years with evidence of significant atherosclerosis, albuminuria, left ventricular hypertrophy, or two or more additional risk factors for cardiovascular disease. The primary outcome of the ACCORD study was a composite of non-fatal myocardial infarction, non-fatal stroke, or death from cardiovascular causes.

The median haemoglobin $\mathrm{A}_{1 \mathrm{C}}$ concentration in the intensive treatment group after randomisation was $6.4 \%,{ }^{13}$ and reached as low as $6.0 \%$ at certain times in some ACCORD clinics. In February 2008, the intensive glycaemia control intervention was stopped early because of higher mortality in this study arm: 1.42 deaths per 100 person years compared with 1.14 deaths per 100 person years in the standard treatment arm (hazard ratio (HR) 1.22, 95\% confidence interval (CI) 1.01 to $1.46 ; \mathrm{P}=0.04) .{ }^{13}$ The intensive treatment group also exhibited significantly higher cardiovascular disease related mortality and did not have a significantly lower incidence of major cardiovascular events compared with patients in the standard treatment arm.

Special attention was given to monitoring and minimising severe hypoglycaemia in the ACCORD study because of concern regarding the consequences of hypoglycaemia in this older population. ${ }^{14}$ No link has been found between the increased mortality observed in the intensive glycaemia control group and severe hypoglycaemia. ${ }^{15}$

A severe hypoglycaemic episode is an important clinical event that causes both physician anxiety and patient distress and that occurs in patients treated both intensively and more conservatively. Identification of risk factors for severe hypoglycaemia can help to guide therapy decisions and ultimately may reduce the risk of such an event. This paper describes both the baseline determinants of severe hypoglycaemia and the relation between the post-randomisation change in haemoglobin $\mathrm{A}_{1 \mathrm{C}}$ levels and the incidence of severe hypoglycaemia in both treatment groups in the ACCORD trial.

\section{METHODS}

Study design

The ACCORD study is a double $2 \times 2$ factorial, randomised, controlled trial designed to test the effect of intensive glucose control compared with standard control on cardiovascular outcomes in patients with type 2 diabetes, and either intensive blood pressure control versus standard control or a lipid strategy that targets low density lipoprotein cholesterol, high density lipoprotein, and triglyceride levels versus a strategy that targets low density lipoprotein cholesterol levels only. ${ }^{1617}$ The full ACCORD study protocol is available at: http://www.accordtrial.org/web/public/docu ments/Protocol\%20All $\% 20$ Chapters.pdf? $\mathrm{CFID}=360349 \& \mathrm{CFTOKEN}=40333908$.

\section{Study participants}

Participants were eligible to enrol in the ACCORD study if they had type 2 diabetes, a haemoglobin $\mathrm{A}_{1 \mathrm{C}}$ concentration of $7.5-11 \%$, and were: $a$ ) between the ages of 40 and 79 years with cardiovascular disease; or b) between the ages of 55 and 79 years with evidence of significant atherosclerosis, albuminuria, left ventricular hypertrophy, or two or more additional risk factors for cardiovascular disease (dyslipidaemia, hypertension, current smoking, or obesity). Key exclusions included a history of frequent or recent serious hypoglycaemic events (hypoglycaemic coma or seizure within the past 12 months or hypoglycaemia 
Table 1|Comparison of hypoglycaemia frequency per 100 person years

\begin{tabular}{|c|c|c|c|c|c|}
\hline \multirow[b]{2}{*}{ Type of hypoglycaemic episode } & \multicolumn{2}{|c|}{ Standard glycaemia control } & \multicolumn{2}{|c|}{ Intensive glycaemia control } & \multirow[b]{2}{*}{$\begin{array}{l}\text { P value for incidence } \\
\text { comparison } \dagger\end{array}$} \\
\hline & $\begin{array}{l}\text { Frequency } \\
(\mathrm{n}(\%))\end{array}$ & $\begin{array}{c}\text { Events* per } 100 \\
\text { person years }\end{array}$ & $\begin{array}{l}\text { Frequency } \\
\quad(n(\%))\end{array}$ & $\begin{array}{c}\text { Events* per } 100 \\
\text { person years }\end{array}$ & \\
\hline \multicolumn{6}{|c|}{ Episodes requiring medical assistance only (HMA; $n=717$ participants) } \\
\hline No hypoglycaemic events & $4913(96.5)$ & \multirow{3}{*}{$\begin{array}{c}\text { Incidence=1.03 } \\
\text { Overall=1.37 }\end{array}$} & $4579(89.5)$ & \multirow{3}{*}{$\begin{array}{c}\text { Incidence=3.14 } \\
\text { Overall=4.28 }\end{array}$} & \multirow{3}{*}{$<0.0001$} \\
\hline One hypoglycaemic event & $134(2.6)$ & & $403(7.9)$ & & \\
\hline Total with $1+$ event & $179(3.5)$ & & $538(10.6)$ & & \\
\hline
\end{tabular}

Episodes requiring either medical or non-medical assistance (HA; $n=1091$ participants)

\begin{tabular}{|c|c|c|c|c|}
\hline No hypoglycaemic events & 4831 (94.9) & \multirow{5}{*}{$\begin{array}{c}\text { Incidence }=1.51 \\
\text { Overall }=2.31\end{array}$} & $4287(83.8)$ & \multirow{5}{*}{$\begin{array}{c}\text { Incidence }=5.05 \\
\text { Overall }=8.25\end{array}$} \\
\hline One hypoglycaemic event & $179(3.5)$ & & $535(10.5)$ & \\
\hline Two hypoglycaemic events & $51(1.0)$ & & $150(2.9)$ & \\
\hline Three or more hypoglycaemic events & $31(0.6)$ & & $145(2.8)$ & \\
\hline Total with $1+$ event & $261(5.1)$ & & $830(16.2)$ & \\
\hline
\end{tabular}

*Incidence calculated as number of initial events divided by total person years of follow-up until initial event or censoring, multiplied by 100 . Overall events per 100 person years of follow-up calculated as total number of events divided by total person years of follow-up until censoring, multiplied by 100 . Numbers of events and participants followed differ slightly from those reported in our analysis relating hypoglycaemic events to mortality ${ }^{15}$ because those analyses only included events occurring before regular visits that ascertained vital status.

${ }^{\dagger}$ Obtained from log rank test.

requiring third party assistance in the past three months with concomitant glucose concentration of less than $3.3 \mathrm{mmol} / \mathrm{l}(60 \mathrm{mg} / \mathrm{dl}))$, unwillingness to do home glucose monitoring, a body mass index of more than 45 , a serum creatinine concentration of more than $133 \mu \mathrm{mol} / \mathrm{l}(1.5 \mathrm{mg} / \mathrm{dl}))$, or other serious illness.

A detailed description of the glycaemia treatment algorithms used in the ACCORD study has been previously published. ${ }^{17}$ Briefly, participants were randomly assigned to receive intensive therapy targeting a haemoglobin $\mathrm{A}_{1 \mathrm{C}}$ concentration of less than $6.0 \%$ or to receive standard therapy targeting a haemoglobin $\mathrm{A}_{1 \mathrm{C}}$ level of 7.0-7.9\%. All participants were provided with glucose lowering medications from a study supervised formulary and glucose monitoring supplies, including glucose meters with software that allowed download of test results at clinic visits. Any marketed glucose lowering medication not in the study formulary could also be prescribed but was not provided by the study.

Treatment regimens were individualised on the basis of study group assignment and response to therapy. Glucose medications were adjusted every two months for participants in the intensive treatment arm and every four months for participants in the standard arm, as needed to reach study goals. Medication adjustments were based on a point of care haemoglobin $\mathrm{A}_{1 \mathrm{C}}$ measurement and data from participants' home blood glucose meters or personal logs. Participants in the intensive arm were asked to self monitor glucose at least two to four times a day if not on insulin and four to eight times a day if on insulin. Haemoglobin $A_{1 C}$ concentration and other measurements used in this report were obtained from blood samples collected at four month clinic visits. All samples were centrally analysed at the ACCORD central laboratory.

A total of 10251 participants were randomised in the ACCORD study: 1174 participants during a 20 week vanguard period from January 2001 to June 2001 and 9077 in the main recruiting period between February 2003 and October 2005. The purpose of the vanguard phase was to assess the feasibility of recruitment, the likelihood of achieving glycaemia and blood pressure treatment goals, and the probability of achieving an acceptable level of adherence in the masked lipid trial. This report includes data submitted to the coordinating centre up until 10 December 2007, which were used by the data and safety monitoring board to make its recommendation to discontinue the intensive glycaemia intervention. The CONSORT diagram for the ACCORD study can be found at: http://content. nejm.org/cgi/data/NEJMoa0802743/DC1/1.

\section{Definition of severe hypoglycaemia}

At each visit, participants were asked about the occurrence, therapy, and consequences of hypoglycaemia, and whether any episodes required them to seek emergency medical care or be admitted to hospital (defined as hypoglycaemia requiring medical assistance (HMA)). Participants were also asked if they had an episode of "low blood glucose" requiring any assistance, either medical or non-medical (hypoglycaemia needing any assistance (HA)). After March 2003, additional documentation of either a plasma glucose level of less than $2.8 \mathrm{mmol} / \mathrm{l}(50 \mathrm{mg} / \mathrm{dl})$ or symptoms that promptly resolved with oral carbohydrate, intravenous glucose, or subcutaneous or intramuscular glucagon was also required for a diagnosis of severe hypoglycaemia. Eighty five per cent of reported cases of HA have such documentation.

Each case of HMA underwent additional review by ACCORD investigators (fully described elsewhere). ${ }^{14}$ Briefly, questions about circumstances surrounding the event were asked, answers were reviewed by a local ACCORD expert in diabetes treatment, and recommendations were made to prevent future episodes. 


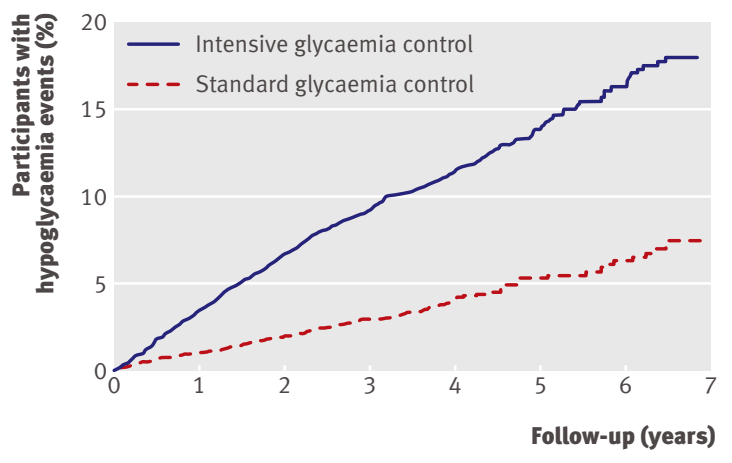

Fig 1 |Plot of Kaplan-Meier estimates of the proportion of participants with at least one episode of hypoglycaemia requiring medical assistance

When a participant had any recurrent episode, additional review by an outside expert was done and haemoglobin $\mathrm{A}_{1 \mathrm{C}}$ targets were relaxed according to protocol (after the third episode). ${ }^{14}$ This report includes all hypoglycaemic events reported up until the time the intensive glycaemia intervention was stopped. ${ }^{13}$

\section{Statistical analysis}

\section{Calculation of hypoglycaemia risk}

Statistical analyses were conducted using SAS software, version 9.1 (SAS Institute Inc, Cary, NC, USA). The number and proportion of participants with recurrent hypoglycaemic events was summarised by glycaemia treatment group. Unadjusted annualised incidence of hypoglycaemia was calculated within glycaemia treatment groups by dividing the number of individuals with events by the cumulative time between randomisation and the initial event or censoring date. In addition, the total number of events per 100 person years of follow-up was calculated by dividing the total number of events by the total number of person years of follow-up. Distribution of the time to first HMA event was compared between treatment groups using Kaplan-Meier curves and log rank tests. Adjusted annual rates of HMA were estimated using Poisson regression models adjusted for age, gender, education, and time since diagnosis of diabetes.

\section{Comparison of HMA risk among baseline subgroups}

Hazard ratios for the risk of HMA in the intensive arm compared with the standard arm were calculated in baseline participant subgroups using Cox proportional hazards regression models containing the baseline variable, the glycaemia intervention effect, and the interaction between the two variables. These models also controlled for age, gender, education, and time since diabetes diagnosis, as well as factors used to stratify randomisation (that is, treatment groups within the blood pressure and lipid trials and the presence of clinical cardiovascular disease). The baseline characteristics were chosen a priori by the investigators on the basis of factors anticipated to be related to hypoglycaemic risk (or possibly mortality). ${ }^{15}$ Cut-off points for continuous variables were also selected a priori.
Development of a predictive model for HMA using baseline characteristics

A more fully adjusted model predictive of the time until initial HMA event was also developed using proportional hazards regression models. Candidate baseline covariates were age, gender, living arrangement (alone or with others), race, education, alcohol use, body mass index, time since diagnosis of diabetes, history of cardiovascular disease, previous amputation of an appendage, history of neuropathy or nerve problems, baseline haemoglobin $\mathrm{A}_{1 \mathrm{C}}$ concentration, albumin to creatinine ratio, serum creatinine concentration, systolic blood pressure, low density lipoprotein cholesterol, use of beta blockers, and use of the following glycaemia medications on entry to the ACCORD trial (pre-randomisation): metformin; sulphonylureas; thiazolidinediones; and any insulin. Forward stepwise variable selection was used to construct a single model based on a $\mathrm{P}$ value of less than 0.05 for the covariates' association with HMA. Interactions between the glycaemia intervention and each covariate identified as important in the above subgroup analyses were also screened for inclusion in the final model (labelled the comprehensive baseline model).

\section{Post-randomisation levels of glucose control and the risk} of $H M A$

The effect of follow-up glucose control on the risk of severe hypoglycaemia was analysed using four different time varying variables to represent glucose control: $a$ ) the updated average haemoglobin $\mathrm{A}_{1 \mathrm{C}}$ during followup (including the baseline measurement); $b$ ) the most recent haemoglobin $\mathrm{A}_{1 \mathrm{C}}$ value; $c$ ) the change in haemoglobin $\mathrm{A}_{1 \mathrm{C}}$ from baseline to the updated average (baseline value excluded from the average); and d) the change in haemoglobin $\mathrm{A}_{1 \mathrm{C}}$ from baseline to the four month value. Given that the values of $a$ through $c$ changed during follow-up, these variables were recalculated for a

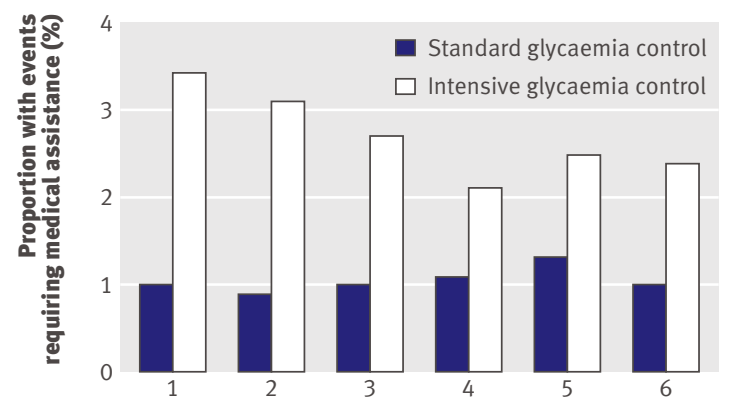

Number at risk

$\begin{array}{llllllll}\begin{array}{l}\text { Number at risk } \\ \text { Standard }\end{array} & 5092 & 4913 & 4660 & 3163 & 1651 & 487 \\ \text { arm } \\ \begin{array}{l}\text { Intensive } \\ 5117\end{array} & 4812 & 4519 & 2998 & 1621 & 441 & \end{array}$ arm

Fig 2 | Annual incidence of hypoglycaemia requiring medical assistance by glycaemia treatment group and follow-up year. Percentages are calculated by subtracting estimates from Kaplan-Meier plots 


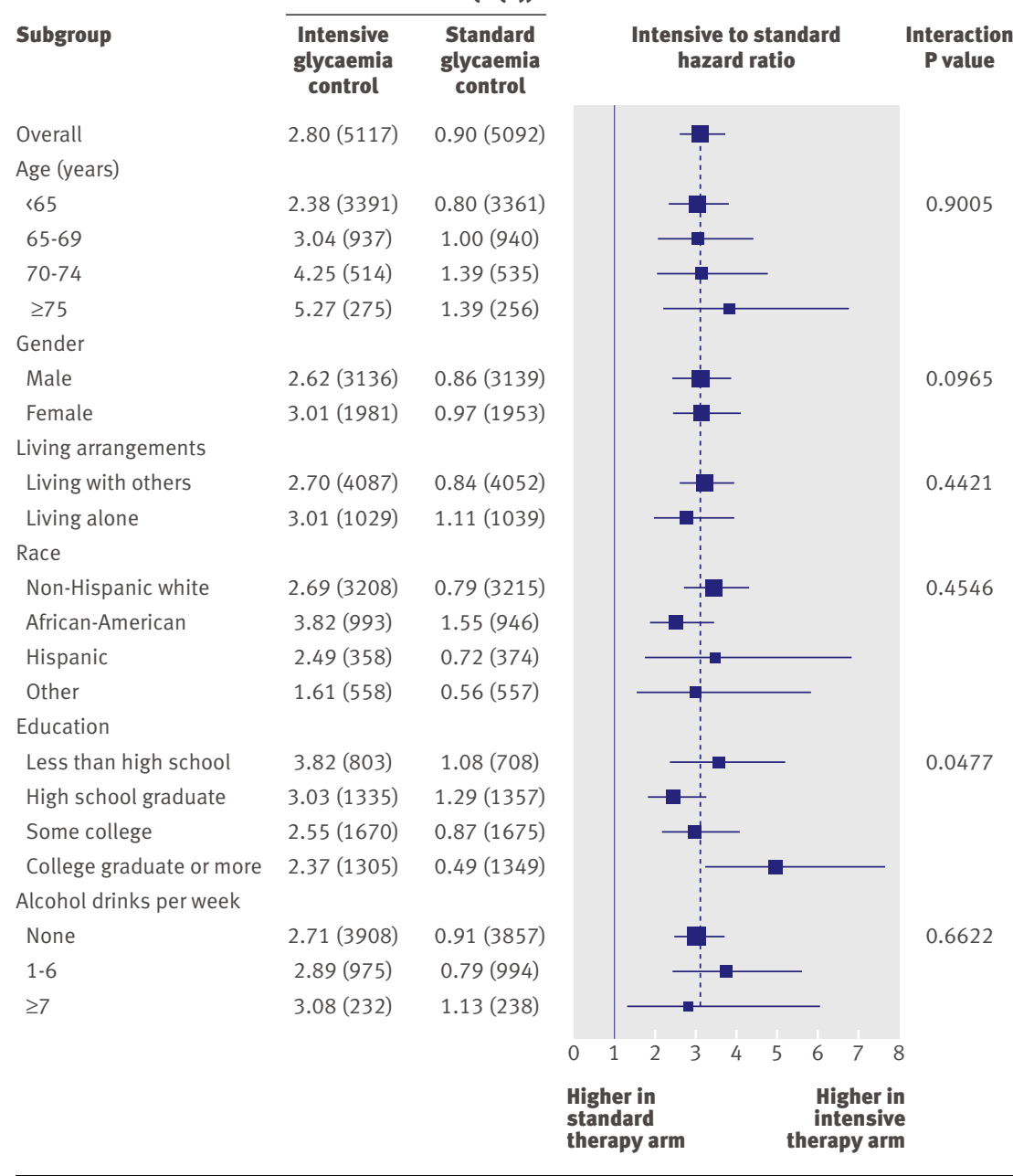

Fig 3 |Risk of hypoglycaemia requiring medical assistance by baseline demographic subgroups. The dashed vertical line represents the overall intensive treatment to standard treatment hazard ratio

\section{RESULTS}

Overall risk of hypoglycaemia

Frequency counts of incident HMA and HA are shown in table 1. Of the 10209 participants in the ACCORD study with any follow-up for severe hypoglycaemia, $717(7.0 \%)$ reported one or more episodes of HMA: 538 individuals in the intensive arm and 179 in the standard arm. In addition, $374(3.7 \%)$ participants never reported an HMA event but reported one or more episodes of severe hypoglycaemia that required only non-medical assistance for treatment.

As expected, rates of both HA and HMA were higher among participants assigned to intensive glycaemia therapy than in those on standard therapy. Among participants in the intensive treatment group $(n=5117), 403(7.9 \%)$ experienced one HMA event, $85(1.7 \%)$ experienced two events, and $50(1.0 \%)$ experienced three or more events. In the standard treatment group $(\mathrm{n}=5092), 134(2.6 \%), 35(0.7 \%)$, and $10(0.2 \%)$ reported one, two, or three or more events, respectively.

The incidence of initial HMA episodes per 100 person years at risk was 3.14 among participants in the intensive arm compared with 1.03 in those in the standard arm (log rank $\mathrm{P}<0.0001)$. Similarly, rates of HA were higher among participants in the intensive arm than among those in the standard arm (5.05 v 1.51; log rank $\mathrm{P}<0.0001)$. When multiple events in the same participant were considered, the overall rates of HMA were 4.28 per 100 person years at risk in the intensive arm compared with 1.37 per 100 person years at risk in the standard arm. The rates for HA were 8.25 and 2.31 per 100 person years at risk in the intensive and standard groups, respectively (see table 1). Kaplan-Meier plots of time to first HMA event by treatment group assignment are shown in fig 1 .

Estimates of annual incidence of HMA were calculated for each follow-up year by subtracting the product limit estimates in the Kaplan-Meier plots from one year to the next (fig 2). The incidence of HMA according to this technique was consistently around $1 \%$ a year in the standard glycaemia control group. Rates were highest among participants in the intensive arm during the first year of follow-up (3.4\%), although the incidence in this group steadily declined in each subsequent year. Only participants recruited during the vanguard phase are represented in year six of follow-up because only vanguard participants were followed for this long. When stratified by recruitment time (vanguard $v$ main trial; data not shown), participants in the intensive arm recruited during the vanguard phase had similar rates of HMA to participants in the intensive arm of the main trial in most years except the initial year, where the rate of HMA in vanguard participants was $5.62 \%$ and in main trial participants was $3.12 \%$.

\section{Hypoglycaemia risk according to baseline subgroups}

The annual incidence of HMA in various subgroups was estimated using Poisson regression after adjustment 


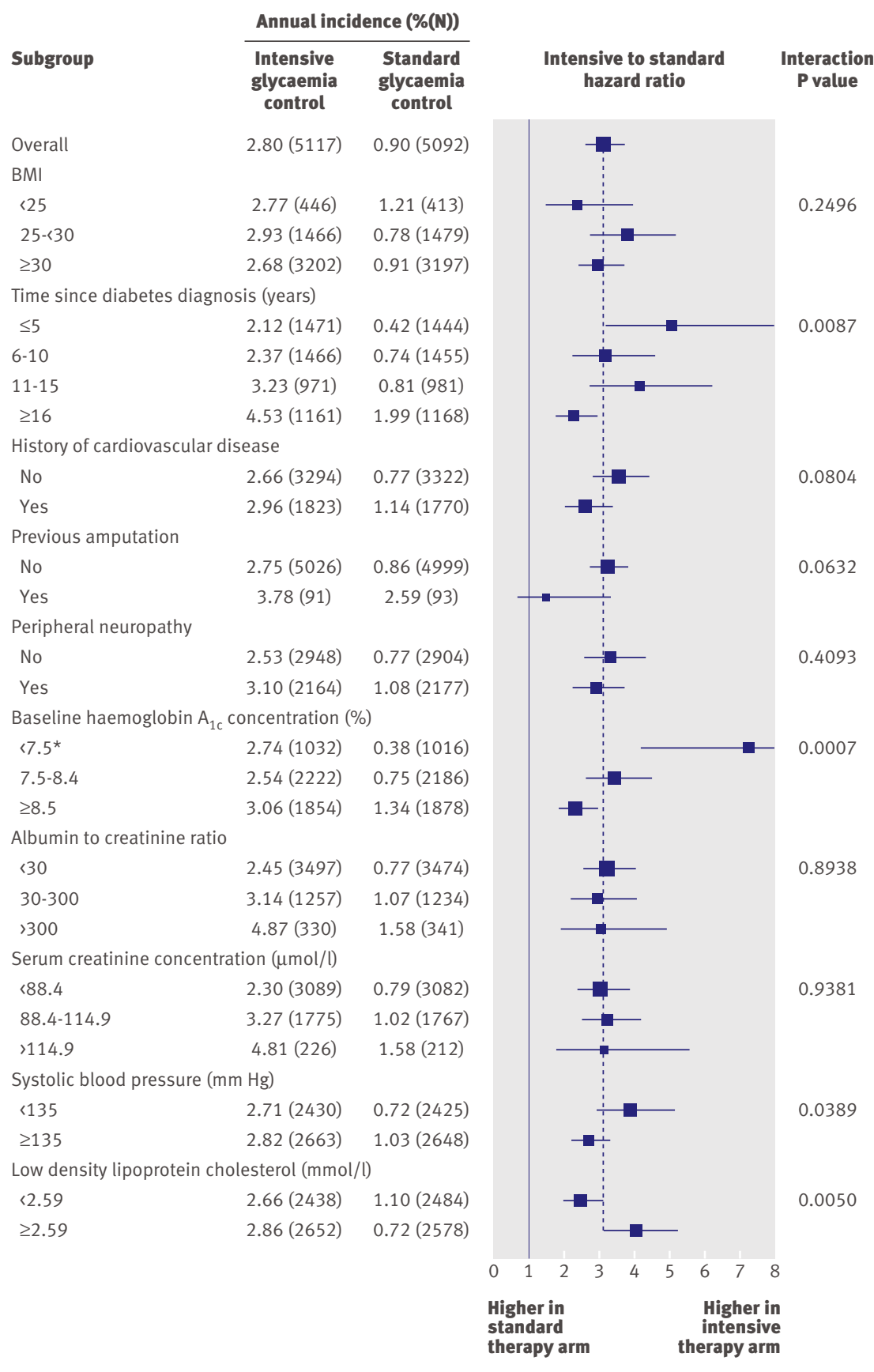

Fig 4 Risk of hypoglycaemia requiring medical assistance by baseline clinical subgroups. The dashed vertical line represents the overall intensive treatment to standard treatment hazard ratio. *Upper $95 \%$ confidence interval of $12.67 \%$ truncated at $8.00 \%$ for haemoglobin $A_{1 C}$ concentration of less than $7.5 \%$ haemoglobin $\mathrm{A}_{1 \mathrm{C}}$ concentration of less than 7.5\% (HR $7.24,95 \%$ CI 4.14 to 12.67$)$; d) systolic blood pressure of less than $135 \mathrm{~mm} \mathrm{Hg}$ (HR 3.88, 95\% CI 2.94 to 5.12); $e$ ) low density lipoprotein cholesterol level of $2.59 \mathrm{mmol} / \mathrm{l}$ (100 mg/dl) or more (HR 4.03, 95\% CI 3.12 to 5.20$) ; f)$ metformin use at baseline (HR 3.79, 95\% CI 2.95 to $4.86) ; g$ ) baseline use of sulphonylureas (HR 4.02, 95\% CI 3.00 to 5.37); and $h$ ) absence of insulin use at baseline (HR 5.42, 95\% CI 3.94 to 7.44).

\section{Baseline predictors of hypoglycaemia}

Analysis of the variables in figs 3-5 by using forward stepwise proportional hazards regression identified 13 independent determinants of HMA. These variables are listed in table 2 and are divided into two classes: those that had similar associations with HMA in both the intensive treatment group and the standard treatment group, and those that had a different relationship with HMA in the intensive versus the standard group (education, low density lipoprotein cholesterol level, use of any insulin at baseline, and baseline level of haemoglobin $\mathrm{A}_{1 \mathrm{C}} ; \mathrm{P}<0.05$ for test of interaction).

Baseline covariates associated with an increased risk for HMA in both the intensive treatment arm and the standard treatment arm were female gender $(\mathrm{P}=0.03)$, African-American race (compared with non-Hispanic whites; $\mathrm{P}<0.0001$ ), history of peripheral neuropathy $(\mathrm{P}=0.0300)$, lower body mass index $(\mathrm{P}<0.0001)$, higher urine albumin to creatinine ratio $(\mathrm{P}<0.0001)$, and higher levels of serum creatinine $(\mathrm{P}=0.0010)$. Each one year increment in baseline age was associated with a $3 \%$ increase in the risk for $\mathrm{HMA}(\mathrm{P}<0.0001)$. For urine albumin to creatinine ratio, participants with macroalbuminuria (ratio $>300$ ) had a higher risk of HMA than those without abnormal elevation in the ratio of urine albumin to creatinine (HR 1.74, 95\% CI 1.37 to 2.21), whereas participants with microalbuminuria (ratio between 30 and 300 inclusive) were also at increased risk (HR 1.20, 95\% CI 1.02 to 1.44). For serum creatinine, participants with renal insufficiency (creatinine level $>114.9 \mu \mathrm{mol} / \mathrm{l}(1.3 \mathrm{mg} / \mathrm{dl}))$ were at highest risk of HMA compared with those who had normal creatinine levels $(<88.4 \mu \mathrm{mol} / \mathrm{l}(1.0 \mathrm{mg} / \mathrm{dl})$; HR 1.66, 95\% CI 1.25 to 2.19 ), and participants with creatinine levels between 88.4 and $114.9 \mu \mathrm{mol} / 1$ inclusive were also at higher risk (HR 1.21, 95\% CI 1.02 to 1.43 ).

For those predictors with different relationships according to glycaemia treatment group, lower education was associated with an increased risk for HMA in both groups, but to a greater degree in the standard treatment group (HR 1.74, 95\% CI 1.02 to 2.95 ) than in the intensive treatment group (HR 1.38, 95\% CI 1.06 to 1.81). Lower levels of low density lipoprotein cholesterol concentration $(<2.59 \mathrm{mmol} / \mathrm{l})$ and higher haemoglobin $\mathrm{A}_{1 \mathrm{C}}$ levels were associated with an increased risk of HMA among participants in the standard treatment group $(\mathrm{P}<0.0001$ for both). Insulin use at randomisation was associated with an increased risk of HMA in both treatment groups $(\mathrm{P}<0.0001$ for both groups, these subgroups, the largest intensive to standard hazard ratios were found among participants with the following characteristics: a) college graduate (HR 4.90, 95\% CI 3.17 to 7.55$)$; b) diagnosed with diabetes 5 years ago or less (HR 5.04, 95\% CI 3.16 to 8.06); c) baseline 
Table 2 | Hazard ratios from model predicting hypoglycaemia requiring medical assistance*

Hazard ratio $(95 \% \mathrm{Cl})$

Pvalue $\dagger$

Effects for both intensive arm participants and standard arm participants

\begin{tabular}{|c|c|c|}
\hline Female ( $v$ male) & $1.21(1.02$ to 1.43$)$ & 0.0300 \\
\hline Race & & $<0.0001$ \\
\hline Non-Hispanic white & 1.0 & \\
\hline African-American & $1.43(1.20$ to 1.71$)$ & $<0.0001$ \\
\hline Hispanic & $0.93(0.68$ to 1.27$)$ & 0.6500 \\
\hline Other & 0.64 (0.47 to 0.88$)$ & 0.0100 \\
\hline History of cardiovascular disease (yes $v$ no) & 1.10 (0.94 to 1.28$)$ & 0.2200 \\
\hline History of peripheral neuropathy (yes $v$ no) & 1.19 (1.02 to 1.38$)$ & 0.0300 \\
\hline Time since diagnosis of diabetes (years) & & 0.7394 \\
\hline$\leq 5$ & 1.0 & \\
\hline 6-10 & $0.98(0.77$ to 1.24$)$ & 0.8500 \\
\hline $11-15$ & $1.06(0.83$ to 1.37$)$ & 0.6200 \\
\hline $16+$ & 1.37 (1.09 to 1.73$)$ & 0.0100 \\
\hline BMI & & 0.0023 \\
\hline$<25$ & 1.0 & \\
\hline$\geq 25$ to $<30$ & 0.78 (0.60 to 1.02$)$ & 0.0700 \\
\hline $30+$ & $0.65(0.50$ to 0.85$)$ & $<0.0001$ \\
\hline Albumin to creatinine ratio & & $<0.0001$ \\
\hline$\ll 30$ & 1.0 & \\
\hline $30-300$ & $1.20(1.02$ to 1.43$)$ & 0.0300 \\
\hline 2300 & 1.74 (1.37 to 2.21$)$ & $<0.0001$ \\
\hline Serum creatinine $(\mu \mathrm{mol} / \mathrm{l})$ & & 0.0010 \\
\hline$<88.4$ & 1.0 & \\
\hline 88.4-114.9 & $1.21(1.02$ to 1.43$)$ & 0.0300 \\
\hline$>114.9$ & $1.66(1.25$ to 2.19$)$ & $<0.0001$ \\
\hline Age (per 1 year increase) & $1.03(1.02$ to 1.05$)$ & $<0.0001$ \\
\hline
\end{tabular}

Effects specific to participants in the standard treatment arm

\begin{tabular}{|c|c|c|}
\hline Education ${ }^{\ddagger}$ & & 0.0274 \\
\hline Less than high school & 1.74 (1.02 to 2.95$)$ & 0.0400 \\
\hline High school graduate & 2.31 (1.46 to 3.66$)$ & $<0.0001$ \\
\hline Some college & 1.62 (1.01 to 2.62$)$ & 0.0500 \\
\hline College graduate or more & 1.0 & \\
\hline $\begin{array}{l}\text { Low density lipoprotein cholesterol level } \\
\left(\geq 2.59 \mathrm{mmol} / \mathrm{l} v<2.59 \mathrm{mmol} / \mathrm{l}^{\ddagger}\right.\end{array}$ & $0.59(0.44$ to 0.80$)$ & $<0.0001$ \\
\hline On any insulin ${ }^{\ddagger}$ & $4.08(2.88$ to 5.76$)$ & $<0.0001$ \\
\hline Haemoglobin $A_{1 C}$ concentration ( $1 \%$ increase) ${ }^{\ddagger}$ & $1.30(1.15$ to 1.47$)$ & $<0.0001$ \\
\hline \multicolumn{3}{|l|}{ Effects specific to participants in the intensive arm } \\
\hline Education $^{\ddagger}$ & & 0.0422 \\
\hline Less than high school & 1.38 (1.06 to 1.81$)$ & 0.0200 \\
\hline High school graduate & 1.15 (0.90 to 1.47$)$ & 0.2600 \\
\hline Some college & $1.02(0.80$ to 1.31$)$ & 0.8600 \\
\hline College graduate or more & 1.0 & \\
\hline $\begin{array}{l}\text { Low density lipoprotein cholesterol level } \\
\left(\geq 2.59 \mathrm{mmol} / \mathrm{l} v<2.59 \mathrm{mmol} / \mathrm{l}^{\ddagger}\right.\end{array}$ & $1.04(0.87$ to 1.24$)$ & 0.6500 \\
\hline On any insulin ${ }^{\ddagger}$ & 1.95 (1.62 to 2.35$)$ & $<0.0001$ \\
\hline Haemoglobin $A_{1 C}$ concentration ( $1 \%$ increase) ${ }^{\ddagger}$ & 1.01 (0.94 to 1.10$)$ & 0.7500 \\
\hline
\end{tabular}

*Estimates are from a model that included all terms listed in the table. Time since diagnosis of diabetes and terms representing assignment to either blood pressure or lipid trial, randomisation to the intensive blood pressure intervention in the blood pressure trial, and randomisation to receive fibrate in the lipid trial were forced into the model.

tFor variables with more than one category, both the overall $P$ value and $P$ values for the specific hazard ratios relative to the reference category are provided.

łEducation, low density lipoprotein cholesterol level, baseline use of insulin, and baseline haemoglobin A1C concentration had relationships with hypoglycaemia that were statistically different between intervention groups. Separate effects are presented within glycaemia groups for these variables. Tests of interactions between characteristics and glycaemia intervention: $\mathrm{P}=0.0405$ for education; $\mathrm{P}=0.0010$ for any insulin use; $\mathrm{P}=0.0090$ for baseline haemoglobin $\mathrm{A} 1 \mathrm{C}$ concentration; and $\mathrm{P}=0.0013$ for low density lipoprotein cholesterol category. but hazard ratio 4.08 in the standard treatment arm and 1.95 in the intensive treatment arm).

Absolute levels of haemoglobin $A_{1 C}$ and hypoglycaemia risk The relationship between glucose control (baseline haemoglobin $\mathrm{A}_{1 \mathrm{C}}$ concentration; updated average haemoglobin $\mathrm{A}_{1 \mathrm{C}}$ concentration; and most recent haemoglobin $\mathrm{A}_{1 \mathrm{C}}$ measurement) and HMA in the intensive treatment and the standard treatment groups is illustrated in fig 6 . When the data for these three measures of glycaemia were divided by quintiles, the crude incidence of severe hypoglycaemia was consistently higher in the intensive group than in the standard group (fig 6A, 6C, and 6E). Within each treatment group, however, higher updated average and most recently measured haemoglobin $\mathrm{A}_{1 \mathrm{C}}$ levels were generally associated with a higher annual incidence of HMA, albeit to different degrees.

Figure 6 also illustrates the effect of these three measures of glycaemia on the hazard for HMA within both the standard and the intensive groups after adjustment for the covariates in table 2. For the standard treatment group, every 1\% unit higher baseline haemoglobin $\mathrm{A}_{1 \mathrm{C}}$ level was associated with a $30 \%$ higher risk of HMA (HR 1.30, 95\% CI 1.15 to 1.47 ; fig $6 \mathrm{~B}$ ). The risk was $76 \%$ higher for every $1 \%$ unit higher updated average haemoglobin $\mathrm{A}_{1 \mathrm{C}}$ concentration (HR 1.76, 95\% CI 1.50 to 2.06; fig 6D). For participants in the intensive treatment group, there was a non-significant relationship between baseline haemoglobin $\mathrm{A}_{1 \mathrm{C}}$ levels and HMA risk (HR 1.01, 95\% CI 0.94 to 1.10; fig 6B). On the other hand, the relationship between updated average haemoglobin $\mathrm{A}_{1 \mathrm{C}}$ concentration and HMA was significant, with a $15 \%$ higher risk for every $1 \%$ unit higher haemoglobin $\mathrm{A}_{1 \mathrm{C}}$ level (HR 1.15, 95\% CI 1.02 to 1.29 ; fig $6 \mathrm{D})$.

Although the patterns of unadjusted incidence rates between treatment groups for the most recent haemoglobin $\mathrm{A}_{1 \mathrm{C}}$ value appear to be very different (fig $6 \mathrm{E}$ ), when adjusted for baseline covariates the model predicted identical, modest relationships between the most recent haemoglobin $\mathrm{A}_{1 \mathrm{C}}$ measurement and HMA risk within both glycaemia groups (fig $6 \mathrm{~F}$; $\mathrm{P}=0.2169$ for a test of different lines within intensive $v$ standard group). Using this model to compare a haemoglobin $\mathrm{A}_{1 \mathrm{C}}$ concentration of $9.0 \%$ with a reference value of $7.5 \%$ predicts a $12 \%$ increase in the risk of HMA for the higher haemoglobin $\mathrm{A}_{1 \mathrm{C}}$ level (HR $1.12,95 \% \mathrm{CI} 1.01$ to 1.24 ), whereas comparing a haemoglobin $\mathrm{A}_{1 \mathrm{C}}$ concentration of $8.5 \%$ with a reference level of $7.5 \%$ predicts a $6 \%$ increase in risk (HR 1.06, $95 \%$ CI 0.99 to 1.14$)$.

\section{Change in haemoglobin $A_{1 C}$ concentration and hypoglycaemia risk}

Similar analyses were done to assess the effect of the change in haemoglobin $\mathrm{A}_{1 \mathrm{C}}$ after randomisation on the risk of HMA. Change was expressed in two ways: a) difference between baseline haemoglobin $\mathrm{A}_{1 \mathrm{C}}$ concentration and four month haemoglobin $A_{1 C}$ level; 


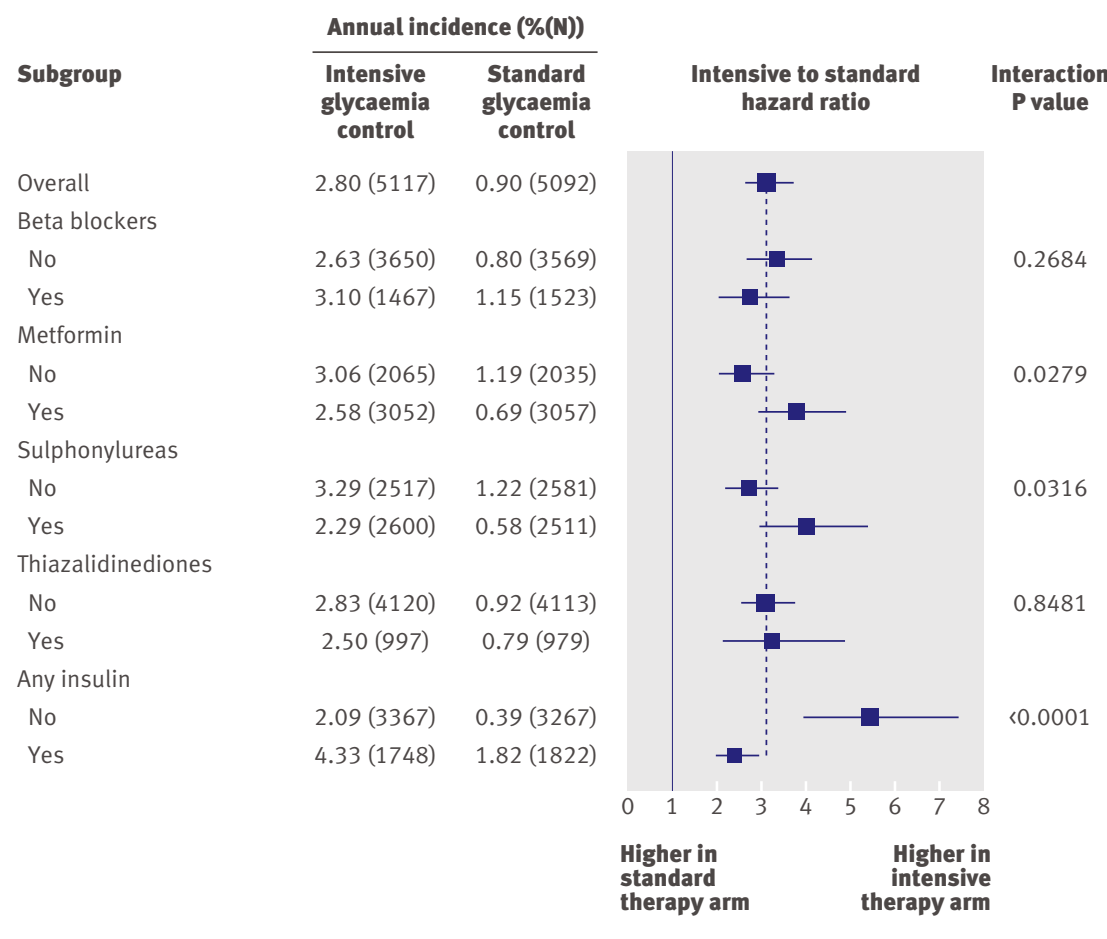

Fig 5 |Risk of hypoglycaemia requiring medical assistance by baseline medication subgroups. The dashed vertical line represents the overall intensive treatment to standard treatment hazard ratio for a $1 \%$ unit decline in haemoglobin $\mathrm{A}_{1 \mathrm{C}}$ concentration from baseline to four months were $22 \%, 19 \%$, $16 \%, 13 \%, 10 \%$, and $6 \%$ for participants starting at haemoglobin $\mathrm{A}_{1 \mathrm{C}}$ levels of 7.5\%, 8.0\%, 8.5\%, 9.0\%, 9.5\%, and $10.0 \%$, respectively.

Similar results were found for the difference between baseline haemoglobin $\mathrm{A}_{1 \mathrm{C}}$ concentration and updated average haemoglobin $\mathrm{A}_{1 \mathrm{C}}$ concentration. Overall, a $1 \%$ unit decline from baseline was predictive of a $35 \%$ $(95 \%$ CI $24 \%$ to $44 \%)$ and a $15 \%(95 \%$ CI $4 \%$ to $24 \%)$ decrease in the risk of HMA within the standard treatment group and the intensive treatment group, respectively. The relationship between the difference in baseline haemoglobin $\mathrm{A}_{1 \mathrm{C}}$ concentration and updated average haemoglobin $\mathrm{A}_{1 \mathrm{C}}$ concentration and the HMA risk was not dependent on the baseline haemoglobin $\mathrm{A}_{1 \mathrm{C}}$ value $(\mathrm{P}=0.2569$ for interaction test).

\section{DISCUSSION}

\section{Principal findings}

As expected, rates of hypoglycaemia were higher among participants assigned to intensive glycaemia therapy than in those on standard therapy. The greater prevalence of HMA compared with events not requiring medical assistance among participants in the ACCORD study may reflect lack of confidence of home care givers in their ability to treat severe hypoglycaemia in elderly fragile patients. This finding emphasises the importance of teaching patients with diabetes how to safely administer oral carbohydrates such as glucose gels or, when needed, subcutaneous injections of glucagon.

Our findings of increased risks for hypoglycaemia among women, African-Americans, the less educated the elderly, those with longer duration diabetes, and those on insulin, regardless of treatment group, will aid clinicians in identifying patients who may benefit from special efforts to prevent hypoglycaemia. Multivariable modelling also identified a history of peripheral neuropathy and biochemical markers of renal dysfunction as independent risk factors for severe hypoglycaemia. These characteristics are consistent with the longer duration of diabetes we saw in participants with a HMA. Given that progressive beta cell dysfunction is a known characteristic of type 2 diabetes, ${ }^{18}$ those participants with a longer duration of diabetes probably had more profound beta cell failure than those who had the disease for less time. Endogenous insulin response to fluctuations in glucose is essentially absent in people with advanced beta cell failure. Our finding of an increased risk of hypoglycaemia in participants with long duration of diabetes likely represents a decreased ability to counter-regulate glucose changes precipitated by glucose lowering medications.

Within both the intensive glycaemia control and the standard glycaemia control groups, participants who had a higher baseline haemoglobin $\mathrm{A}_{1 \mathrm{C}}$ concentration had an increased risk of HMA. After controlling for other baseline covariates, this effect was only seen in the standard treatment group. Rapid lowering of 

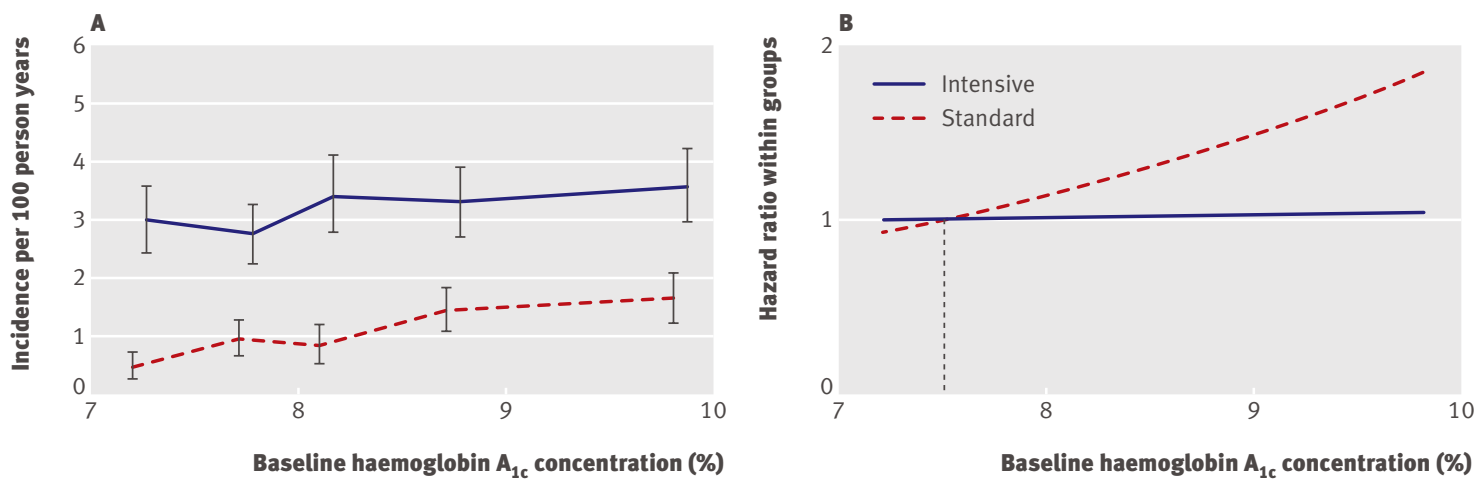

Baseline haemoglobin $\mathbf{A}_{1 \mathrm{c}}$ concentration (\%)
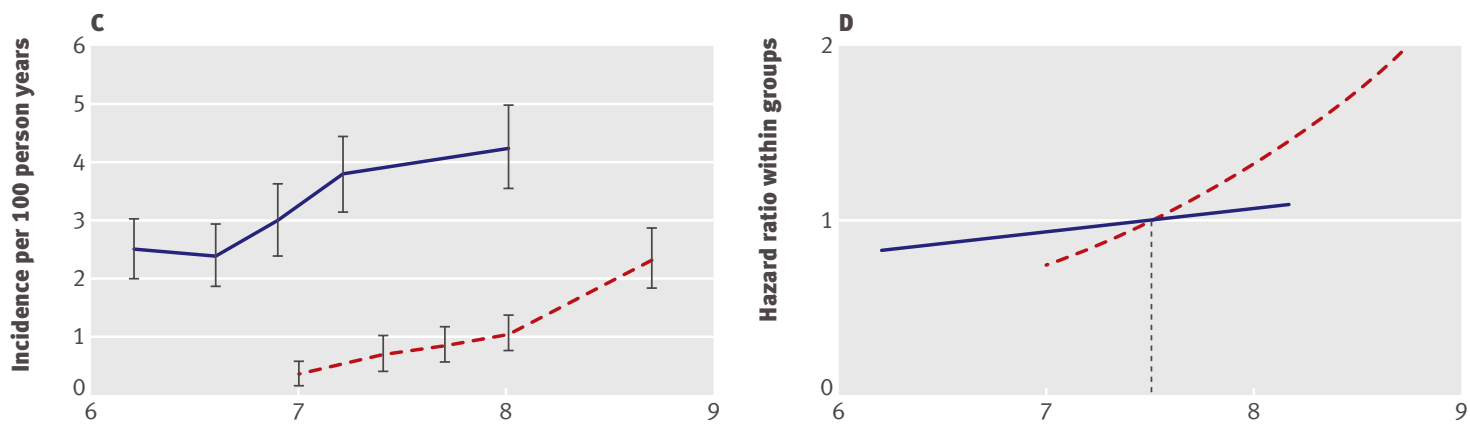

Updated average haemoglobin $\mathbf{A}_{1 \mathrm{c}}$ concentration (\%)

Updated average haemoglobin $A_{1 c}$ concentration (\%)
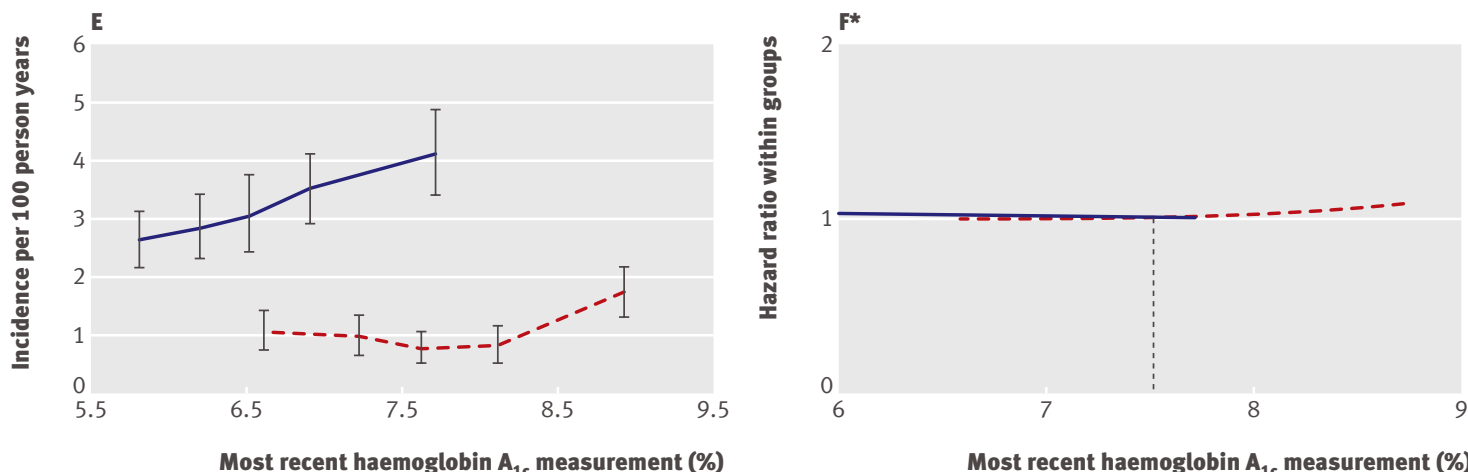

Most recent haemoglobin $A_{1 c}$ measurement (\%)

Fig 6 | (A) Incidence (95\% Cl) of HMA by quintiles of baseline haemoglobin $\mathrm{A}_{1 \mathrm{C}}$ concentration. (B) Hazard ratio for baseline haemoglobin $A_{1 C}$ concentration relative to a haemoglobin $A_{1 C}$ concentration of $7.5 \%$ (dotted line). (C) Incidence $(95 \% \mathrm{Cl})$ of hypoglycaemia requiring medical assistance (HMA) by updated average haemoglobin $A_{1 c}$ concentration. (D) Hazard ratio for updated average haemoglobin $A_{1 C}$ concentration relative to a haemoglobin $A_{1 C}$ concentration of $7.5 \%$ (dotted line). (E) Incidence $(95 \% \mathrm{Cl})$ of HMA by most recent haemoglobin $A_{1 C}$ measurement. (F) Hazard ratio for most recent haemoglobin $A_{1 C}$ measurement relative to a haemoglobin $A_{1 C}$ concentration of $7.5 \%$ (dotted line) ${ }^{\star}$ *The model depicted in (F) contains a significant quadratic term $(P=0.04)$, whereas the models depicted in $(B)$ and $(D)$ were found to be linear on the log scale

haemoglobin $\mathrm{A}_{1 \mathrm{C}}$ level during the first four months of the study was not associated with a higher risk of severe hypoglycaemia. On the contrary, participants whose haemoglobin $\mathrm{A}_{1 \mathrm{C}}$ concentration did not drop quickly in the first four months had an increased risk of hypoglycaemia. These patients were usually on insulin at baseline and may have subsequently been treated with higher insulin doses or different combinations of medications in a potentially unsuccessful attempt to lower their haemoglobin $\mathrm{A}_{1 \mathrm{C}}$ concentration. Whereas detailed analyses of the contribution of specific glucose lowering therapies to the risk of severe hypoglycaemia are beyond the scope of this paper, this unexpected observation suggests that clinicians should not persist in trying to intensify glycaemic therapy when a patient's haemoglobin $A_{1 C}$ level does not fall. Instead, it may be wiser to ascertain that the patient understands and can adhere to their treatment regimens.

Extensive efforts were made to reduce severe hypoglycaemia in the ACCORD study, including review (with feedback) of rates and episodes by both internal and external experts. ${ }^{14}$ Staff were trained to deliver patient education and provided participants with educational materials on hypoglycaemia awareness. All participants were taught to self monitor blood glucose concentration and were educated on the effect of lifestyle changes on risk for hypoglycaemia and how to recognise and self treat hypoglycaemia, such as keeping glucose tablets (provided by the study) available at all times. The reduction after the first year in the annual 

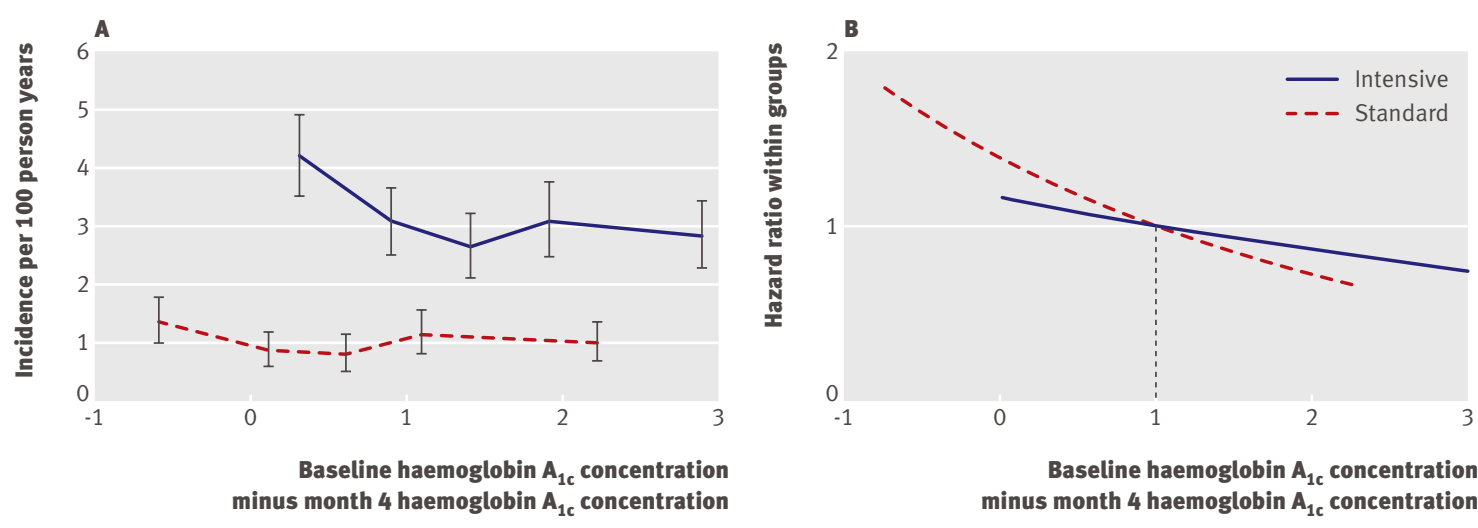

Fig $7 \mid$ (A) Incidence $(95 \% \mathrm{Cl})$ plotted against quintiles of change in haemoglobin $\mathrm{A}_{1 \mathrm{c}}$ concentration between baseline and four months. (B) Hazard ratio for four month change in haemoglobin $A_{1 C}$ concentration relative to a $1 \%$ unit decline

incidence of hypoglycaemia among participants recruited in the vanguard phase and randomised to the intensive treatment group suggests that experience with intensive glucose lowering on the part of the participant and the care team is important in reducing the risk of hypoglycaemia.

\section{Comparison with other studies}

The rates of severe hypoglycaemia measured in the ACCORD study were greater than those observed in the ADVANCE study ${ }^{5}$ and less than those seen in $\mathrm{VADT}^{7}$ the two recently reported studies also designed to determine whether improving glucose control would reduce cardiovascular events in people with type 2 diabetes. More than $75 \%$ of the participants in the intensive treatment group of the ACCORD study were prescribed insulin - a therapy known to increase hypoglycaemia risk-for some portion of follow-up, compared with $40 \%$ of participants in the intensive treatment arm of the ADVANCE study. More than half of the participants in VADT were already on insulin at baseline, and the haemoglobin $\mathrm{A}_{1 \mathrm{C}}$ concentration achieved in the intensive treatment group was higher than that in the ACCORD study (6.9\% $v 6.4 \%$, respectively).

It is difficult to compare the rates of hypoglycaemia in the ACCORD study with those reported in community surveys because of the variety of methods used to define hypoglycaemia, but one survey found that the estimated proportion of individuals who reported a biochemical episode of hypoglycaemia (finger stick glucose concentration $<3.33 \mathrm{mmol} / \mathrm{l}(60 \mathrm{mg} / \mathrm{dl})$ ) was $9.4 \%$ for those using an oral hypoglycaemia agent and $19.9 \%$ among those using insulin. ${ }^{19}$ A community based report from the United Kingdom found that $7 \%$ of people on a sulphonylurea and $7-25 \%$ of those on insulin experienced an episode of severe hypoglycaemia requiring any assistance during a 9-12 month period..$^{20}$ In the ACCORD study, the proportion of participants in the intensive glycaemia control group who reported an episode of severe hypoglycaemia after 3.3 years of follow-up (HA $16.2 \%$; $>75 \%$ ever prescribed insulin therapy) was lower than that found among community patients using insulin. ${ }^{21}$

\section{Study strengths and limitations}

The collection of detailed information on hypoglycaemic events for a large number of individuals comprises one of many strengths of this investigation. Standardised procedures were used for documentation of events within both the intensive and the standard glycaemia control groups. Our study does, however, have several limitations.

Firstly, severe hypoglycaemia was self reported by participants, and validation required participants to self measure blood glucose levels if hypoglycaemia was suspected. Participants may not have experienced hypoglycaemic symptoms severe enough to prompt a measurement of finger stick glucose, even when blood glucose levels were less than $2.78 \mathrm{mmol} / 1$ (50 mg/dl; hypoglycaemia unawareness). If so, our estimates of the incidence of hypoglycaemic events would be too low. The ACCORD study purposely focused on the occurrence of severe hypoglycaemia because of the dangers associated with this condition, and did not track events that did not meet the prespecified study definition. The American Diabetes Association recommends that blood glucose concentrations of less than $3.89 \mathrm{mmol} / \mathrm{l}(70 \mathrm{mg} / \mathrm{dl})$ be considered indicative of hypoglycaemia. ${ }^{22}$ Using this standard, it is probable that participants in the ACCORD study experienced many more episodes of modest hypoglycaemia than were reported. With our data, we could not determine whether severe hypoglycaemia was more common in participants who experienced frequent episodes of modest hypoglycaemia than in those who experienced little modest hypoglycaemia.

Secondly, all participants were instructed to report episodes of severe hypoglycaemia within 24 hours of occurrence. Participants in the intensive treatment group had more contacts with clinic staff, however, so they had more opportunities to recall these episodes. Moreover, it is possible that more frequent use of finger stick blood glucose monitors in the intensive treatment 


\section{WHAT IS ALREADY KNOWN ON THIS TOPIC}

Intensive glycaemia control in patients with type 2 diabetes increases the risk of an episode of severe hypoglycaemia

Hypoglycaemia may prevent patients with diabetes from achieving excellent glycaemic control

\section{WHAT THIS STUDY ADDS}

In the ACCORD study, patients with poor glycaemic control (higher baseline haemoglobin $A_{1 C}$ concentration) had a greater risk of hypoglycaemia than those with better glycaemic control, regardless of treatment group

A greater drop in haemoglobin $A_{1 c}$ concentration between baseline and four months was not associated with an increased risk of hypoglycaemia

Individuals started on intensive treatment who do not respond promptly with a fall in haemoglobin $A_{1 C}$ concentration may be more likely to experience severe hypoglycaemia than those who respond promptly to intensification of treatment with a more rapid decline in haemoglobin $\mathrm{A}_{1 \mathrm{C}}$ level group resulted in a higher degree of awareness and more use of medical assistance.

Thirdly, the ACCORD study did not collect sufficient data to accurately detect episodes of hypoglycaemia unawareness, some of which may have been severe episodes of hypoglycaemia. This shortcoming would have underestimated the rates of severe hypoglycaemia.

Finally, as with all post hoc epidemiologic analyses, our results may be confounded by unmeasured factors such as participants' adherence to their glycaemic management regimens or the rationale behind investigators' decisions to alter drugs or doses in the context of mild hypoglycaemia.

\section{Conclusions}

Severe hypoglycaemia was more common in participants in the ACCORD study randomised to intensive glycaemia control than in those randomised to standard glycaemia control. In multivariable analyses, women, African-Americans, older participants, those prescribed insulin therapy, and those with lower levels of educational achievement were at increased risk for severe hypoglycaemia. Participants who were started on intensive treatment and did not respond promptly with a fall in haemoglobin $A_{1 C}$ concentration were more vulnerable to severe hypoglycaemia and its possible consequences.

These observations can provide guidance to clinicians who attempt to intensify patient therapy and adjust glycaemic treatment goals on the basis of individual risk, as has been recommended in the latest statement from the American Diabetes Association. ${ }^{23}$ Future studies should be directed at developing strategies to reduce severe hypoglycaemia in high risk groups.

Contributors: MEM contributed to the development of the protocol and the design, performed analyses for the study, participated in data interpretation, and wrote the majority of the first draft. DEB, HCG, and ERS contributed to the development of the protocol and to the design, participated in data interpretation, and wrote portions of the first draft. RMB contributed to the development of the protocol, participated in data interpretation, and edited the manuscript. JCE participated in data interpretation and editing of the manuscript results and discussion sections. RDC managed study participants and participated in data interpretation and editing of the manuscript. TEC contributed to development of study manuals, performed analyses for the study, and undertook data analysis and writing and review of the first draft. RMC participated in the study's implementation, managed study patients, and took part in interpretation and editing of the manuscript. GD participated in data collection, interpretation of analyses, and editing of the manuscript. MNF contributed to development of the paper and wrote a portion of the first draft. FIB contributed to development of the paper, interpretation of the results, and editing of the manuscript. JFL contributed to development of the operations manual and participated in development of the methods section and editing of the manuscript. PJO participated in the study design, conceptualisation of the paper, and editing of the manuscript. TP participated in data interpretation and editing of the manuscript. PJS participated in protocol development, trial operations, and planning and writing of portions of the first draft. UKS contributed to the presentation and interpretation of the analyses and writing portions of the first draft. AS contributed to execution of the study, participated in the interpretation of the data, and helped in the editing of the manuscript. SG participated in protocol development, internal monitoring of hypoglycaemia rates during the study, and interpretation and writing a portion of the first draft. All authors approved the final draft. MEM is the guarantor.

Funding: The authors were supported by contracts from the National Heart Lung and Blood Institute (N01-HC-95178, N01-HC-95179, N01-HC-95180, N01-HC-95181, N01-HC-95182, N01-HC-95183, N01-HC-95184, IAA-Y1-HC9035, and IAA-Y1-HC-1010), by other components of the National Institutes of Health -including the National Institute of Diabetes and Digestive and Kidney Diseases, the National Institute on Aging, and the National Eye Institute -by the Centers for Disease Control and Prevention, and by General Clinical Research Centers. The following companies provided study medications, equipment, or supplies: Abbott Laboratories, Amylin Pharmaceutical, AstraZeneca, Bayer HealthCare, Closer Healthcare, GlaxoSmithKline, King Pharmaceuticals, Merck, Novartis, Novo Nordisk, Omron Healthcare, SanofiAventis, and Schering-Plough

Competing interests: MEM has received honorariums for consulting from Hoffman-LaRoche. HCG has received research grants and honorariums for consulting and speaking from the following companies that manufacture glucose lowering medications: Sanofi-Aventis, GlaxoSmithKline, and Merck. He has also received honorariums for consulting and/or speaking from NovoNordisk, Lilly, Roche, BristolMyersSquibb, and AstraZeneca. HCG holds the Population Health Institute chair in diabetes research sponsored by Aventis. ERS has served as a consultant for Merck and has reviewed applications for the Pfizer Visiting Professorship Program. RMB and RMC have served as principal investigator or coinvestigator for industry sponsored clinical trials research. All honorariums, speaking fees, consulting fees, and research and educational support are paid directly to the non-profit International Diabetes Center, of which RMB and RMC are salaried employees. JCE is a member of Merck and Sanofi-Aventis speaker's bureau and holds a clinical grant funded by Merck. RDC has received honorariums for consulting and speaking from the following companies that manufacture glucose lowering medications: Sanofi-Aventis, GlaxoSmithKline, and Merck. He has also received honorariums for consulting and/or speaking from Pfizer and has served as a consultant for NovoNordisk. GD has served as an investigator, speaker, and occasional consultant for SanofiAventis and Merck, and as an investigator for NovoNordisk, Eli Lilly/ Amylin, Mannkind, Pfizer, Boeringer Ingelheim, Novartis, GlaxoSmithKline, and BristolMyersSquibb. JFL has received honorariums from the American Academy of Physician Assistants, Amylin, AstraZeneca, NovoNordisk, and Smith's Medical, has been a consultant for AstraZeneca, and has received grants or research support from the following companies: Amylin; Hoffman-LaRoche; Medtronic; NovoNordisk; Novartis; Osiris; Pfizer; National Institutes for Heath/ National Heart, Lung, and Blood Institute; Tranistion Therapeutics; and Tolerx. AS has received consulting honorariums from Pfizer, Novartis, and Medtronic, speaking fees from Pfizer, and was a principal investigator of a clinical trial sponsored by Sanofi-Aventis. SG has been a consultant for Merck and Sanofi-Aventis, and owns stock in Johnson and Johnson and in Novartis ( $\$ 5000$ each). The remaining authors have no competing interests.

Ethical approval: This study was approved by the Wake Forest University Health Sciences institutional review board and the review boards of all participating institutions. Written, informed consent was provided by all participants.

Data sharing: No additional data available at this time. 
1 Desouza C, Salazar H, Cheong B, Murgo J, Fonseca V. Association of hypoglycemia and cardiac ischemia: a study based on continuous monitoring. Diabetes Care 2003;26:1485-9.

2 Cryer PE. Hypoglycaemia: the limiting factor in the glycaemic management of type I and type II diabetes. Diabetologia 2002;45:937-48.

3 Cryer PE. The barrier of hypoglycaemia in diabetes. Diabetes 2008;57:3169-76

4 DCCT Research Group. Epidemiology of severe hypoglycemia in the Diabetes Control and Complications Trial. Am J Med 1991;90:450-9.

5 Patel A, MacMahon S, Chalmers J, Neal B, Billot L, Woodward M, et al for the ADVANCE Collaborative Group. Intensive blood glucose control and vascular outcomes in patients with type 2 diabetes. $N$ Engl J Med 2008;358:2560-72.

6 UKPDS Study Group. Intensive blood-glucose control with sulphonylureas or insulin compared with conventional treatment and risk of complications in patients with type 2 diabetes (UKPDS 33). Lancet 1998;352:837-53.

7 Duckworth W, Abraira C, Moritz T, Reda D, Emanuele N, Reaven PD, et al for the VADT Investigators. Glucose control and vascular complications in veterans with type 2 diabetes. N Engl J Med 2009;360:129-39.

8 Leese GP, Wang J, Broomhall J, Kelley P, Marsden A, Morrison W, et al for the DARTS/MEMO collaboration. Frequency of severe hypoglycemia requiring emergency treatment in type 1 and type 2 diabetes; a population-based study of health service resource use. Diabetes Care 2003;26:1176-80.

9 Gurlek A, Erbas T, Gedik O. Frequency of severe hypoglycaemia in type 1 and type 2 diabetes during conventional insulin therapy. Exp Clin Endocrinol Diabetes 1999;107:220-4.

10 Henderson JN, Allen KV, Deary J, Frier BM. Hypoglycaemia in insulintreated type 2 diabetes: frequency, symptoms and impaired awareness. Diabet Med 2003;20:1016-21.

11 Donnelly LA, Morris AD, Frier BM, Ellis JD, Donnan PT, Durrant R, et al for the DARTS/MEMO Collaboration. Frequency and predictors of hypoglycaemia in type 1 and insulin-treated type 2 diabetes: a population based study. Diabet Med 2005;22:449-55.

12 Amiel SA, Dixon T, Mann R, Kameson K. Hypoglycaemia in type 2 diabetes. Diabet Med 2008;25:245-54
13 Gerstein HC, Miller ME, Byington RP, Goff DC Jr, Bigger JT, Buse JB, et al for the ACCORD Study Group. Effects of intensive glucose lowering in type 2 diabetes. N Engl J Med 2008;358:2545-59.

14 Bonds DE, Kurashige EM, Bergenstal R, Brillon D, Domanski M, Felicetta JV, et al for the ACCORD Study Group. Severe hypoglycemia monitoring and risk management procedures in the Action to Contro Cardiovascular Risk in Diabetes (ACCORD) trial. Am J Cardiol 2007;99:80i-9i.

15 Bonds DE, Miller ME, Bergenstal RM, Buse JB, Byington RP, Cutler JA, et al. The association between symptomatic, severe hypoglycaemia and mortality in type 2 diabetes: retrospective epidemiological analysis of the ACCORD study. BMJ 2009;339:b4909.

16 Buse JB, Bigger JT, Byington RP, Cooper LS, Cushman WC, Friedewald WT, et al for the ACCORD Study Group. Action to Control Cardiovascular Risk in Diabetes (ACCORD) trial: design and methods Am J Cardiol 2007;99:21i-33i.

17 Gerstein HC, Riddle MC, Kendall DM, Cohen RM, Goland R, Feinglos MN, et al for the ACCORD Study Group. Glycemia treatment strategies in the Action to Control Cardiovascular Risk in Diabetes (ACCORD) trial. Am J Cardiol 2007;99:34i-43i.

18 Prentki M, Nolan CJ. Islet beta cell failure in type 2 diabetes. J Clin Invest 2006;116:1802-12.

19 Miller CD, Philips LS, Ziemer DC, Gallina DL, Cook CB, El-Kebbi IM. Hypoglycemia in patients with type 2 diabetes mellitus. Arch Intern Med 2001;161:1653-9.

20 UK hypoglycemia study group. Risk of hypoglycaemia in types 1 and 2 diabetes: effects of treatment modalities and their duration. Diabetologia 2007;50:1140-7.

21 Zammet NN and Frier BM. Hypoglycemia in type 2 diabetes: Pathophysiology, frequency, and effects of different treatment modalities. Diabetes Care 2005;28:2948-61.

22 American Diabetes Association Workgroup on Hypoglycemia. Defining and reporting hypoglycemia in diabetes. Diabetes Care 2005;28:1245-9.

23 Skyler JS, Bergenstal R, Bonow RO, Buse J, Deedwania P, Gale EAM, et al. Intensive glycemic control and the prevention of cardiovascular events: implications of the ACCORD, ADVANCE and VA diabetes trials. J Am Coll Cardiol 2009;53:298-304.

Accepted: 16 November 2009 